\title{
Prevention of kidney injury after myocardial ischemia reperfusion is achievable with short-term protein restriction
}

\author{
Baran Hashemi ${ }^{1,2}{ }^{\mathbb{D}}$, Majid Maleki ${ }^{1}$, Amir Darbandi Azar ${ }^{1}$, Morteza Zare $^{2}$, Seyed Mohammad \\ Mazloomi $^{*} \mathbb{D}$, Nasim Naderi ${ }^{1}$ \\ ${ }^{1}$ Rajaie Cardiovascular, Medical and Research Center, Iran University of Medical Sciences, Tehran, Iran \\ ${ }^{2}$ Nutrition Research Center, Department of Food Hygiene and Quality Control, School of Nutrition and Food Sciences, Shiraz University \\ of Medical Sciences, Shiraz, Iran
}

\section{ART I C L E IN F O}

Article Type:

Original

\section{Article History:}

Received: 14 June 2019

Accepted: 30 August 2019

Published online: 15 September 2019

Keywords:

Protein restriction

Kidney

Myocardial reperfusion injury

Blood urea nitrogen

Inflammation

Glucose

\begin{abstract}
A B S T R A C T
Introduction: Kidney injury is a serious complication after cardiovascular surgery. Left ventricular dysfunction, pre-operative kidney dysfunction and inflammation can predict kidney injury after myocardial reperfusion.

Objectives: We aimed to study whether short-term protein restriction (PR) would influence blood urea nitrogen (BUN) levels after myocardial reperfusion injury.

Materials and Methods: Male Wistar rats fed with either AIN-93M or AIN-93M protein restricted diet one week before myocardial reperfusion injury. After surgery, feeding continued with AIN-93M for 1 week.

Results: BUN levels increased significantly compared to the pre-operative level in the control group $(P=0.03)$ and decreased significantly in the protein-restricted group $(P=0.01)$. Multivariate analysis showed that $P R$ through its effect on blood glucose $(\beta=1.2,95 \% \mathrm{CI}=0.1$ 2.34), IL-6 $(\beta=-2.22,95 \% \mathrm{CI}=-3.9--0.54)$ and left ventricular ejection fraction (LVEF) $(\beta=-1.21,95 \% \mathrm{CI}=-2.34-0.09)$ was able to protect the kidney from myocardial reperfusion. Conclusion: Short-term PR through modulating pre-operative IL-6, post-operative blood glucose levels and LVEF could prevent kidney injury after myocardial reperfusion injury.
\end{abstract}

\section{Implication for health policy/practice/research/medical education:}

Cardiovascular disease is the leading cause of mortality globally. Reperfusion injury is unavoidable in common treatment of cardiovascular disease like angioplasty and coronary artery bypass graft (CABG) surgery. Efforts to alleviate reperfusion injury through pharmacologic treatments and ischemic conditioning have been disappointing so far. Short-term PR is a non-invasive, clinically feasible and low-cost intervention. We found a beneficial effect of PR in reducing kidney injury after heart surgery. Further studies are required to assess compliance, safety and effectiveness of such dietary manipulation in the clinical setting. Please cite this paper as: Hashemi B, Maleki M, Azar A, Zare M, Mazloomi SM, Naderi N. Prevention of kidney injury after myocardial ischemia reperfusion is achievable with short-term protein restriction. J Renal Inj Prev. 2019; 8(4): 301-305. DOI: 10.15171/jrip.2019.55.

\section{Introduction}

Kidney injury after surgeries with reperfusion to organs is a serious complication (1) and may result in infection, dialysis dependency, and high mortality rate. Left ventricular dysfunction, pre-operative kidney dysfunction and inflammation can be predictive of the kidney function after heart surgery (2). Additionally, blood glucose control was shown to protect the kidney function in critically ill patients (3).

Some pharmacological agents and non-pharmacological strategies had some promising results, but there is no consensus on one single method to reduce injury or to treat the established injury (4). Ischemic preconditioning, for instance, is known as the most powerful strategy to reduce myocardial reperfusion injury (5). In insulin resistance status, which is a common phenomenon in surgeries, ischemic preconditioning failed to reduce reperfusion injury (6). Furthermore, ischemic preconditioning cannot prevent dialysis dependency and mortality (7).

Dietary restriction is defined as reducing food intake without causing malnutrition (8). Short-term dietary restriction has been evaluated for its impact on the 
consequences of acute stress resistance showing antiinflammatory (9), organ protection, and functional recovery benefits (10). Protein or single amino acid restriction, regardless of calorie intake, was found to contribute to preconditioning against reperfusion injury (11). Dietary preconditioning from protein restriction (PR) was demonstrated in preclinical models of kidney ischemia/reperfusion and focal stroke as the two major complications of heart surgery in the short period of 6 to 14 days $(10,12)$.

Blood urea nitrogen (BUN) is one of the routinely measured biomarkers for assessing post-operative kidney function (13). It was known that renal dysfunction and accumulation of uremic toxins leads to unfavorable outcome after heart surgery (14).

\section{Objectives}

We aimed to study whether short-term PR would influence BUN levels after myocardial reperfusion injury (MRI). Moreover, we aimed to explore what factors mediate this possible pre-conditioning effect.

\section{Materials and Methods}

\section{Animals and diet}

Male Wistar rats (Pasteur Institute, Tehran, Iran), weighing 300-350 g, were acclimated for one month. Seven days before myocardial reperfusion, the rats were randomly fed with either AIN-93M or AIN-93M protein restricted diet (Figure 1) in which protein was substituted with carbohydrates (Altromin Spezialfutter GmbH \& Co. KG, Germany). After MRI, feeding continued with AIN93M for one week. Food and fluid intake were assessed daily. On day seven after MRI, the rats were sacrificed with deep anaesthesia.

\section{Myocardial ischemia/reperfusion model}

Anesthesia was performed with intraperitoneal injection of xylazine $2 \%(8.7 \mathrm{mg} / \mathrm{kg})$ and ketamine $10 \%(43 \mathrm{mg} / \mathrm{kg})$. The surgical area was completely shaved and sterilized with ethanol 70\%. The endotracheal intubation was performed and the rats were connected to a small animal pressure controlled ventilator (CW-SAR1000). Body temperature was maintained by a heating pad at $37 \pm 1^{\circ} \mathrm{C}$. Following pericardiotomy, the left anterior descending artery was ligated by a double knot prolene suture for a 30-minute ischemic period. Reperfusion was allowed by cutting the suture. Rats were weaned from mechanical ventilation when they became ambulatory.

\section{Body weight assessment}

Body weight was measured three times; before dietary manipulation, before surgery, and at the end of the study.

\section{Blood glucose measurements}

Blood glucose was measured by glucose meter (Glucocard 01, Arkray, Inc. Japan) on fresh blood according to the manufacturer's instruction. Measurements were done before MRI, $48 \mathrm{~h}$ after that, and at the end of the study.

\section{Serum analysis}

Serum was separated by centrifuging at $4000 \mathrm{~g}$ for 10 minutes at $4^{\circ} \mathrm{C}$ and stored at $-80^{\circ} \mathrm{C}$ until analysis. BUN was assessed by autoanalyzer BT1500(Biotecnica Company, Italy). Interleukin 6 (IL-6) (Abcam, UK) and Lactate dehydrogenase (LDH) (Cloud-Clone Crop, US) were measured by commercial ELISA kits. Assessments were performed before MRI and at the end of the study. Blood was drawn from tail vein before surgery and from the chest cavity at the end of the study.

\section{Echocardiographic measurements}

Transthoracic echocardiography was done using variable frequency harmonic phased-array transducer (General Electric-Vingmed Ultrasound, Horten Norway) at 12 MHZ. Myocardium left ventricle (LV) dimensions were measured using 2-dimensional $\mathrm{M}$-mode LV imaging at the rate of 100 frames per second and a depth setting of $20 \mathrm{~mm}$ in the parasternal long- and short-axis views. Ejection fraction (EF) was calculated as follows; $(\mathrm{EF}[\%]=[$ LVEDD2 - LVESD2] / [LVEDD2] $\times 100)$. Measurements were done before MRI induction and at the end of the study. A cardiologist expert in small animal echocardiography who was blinded to the study groups performed the measurements (15).

\section{Ethical issues}

All the experiments were performed based on medical research ethics in the care and use of laboratory animals,
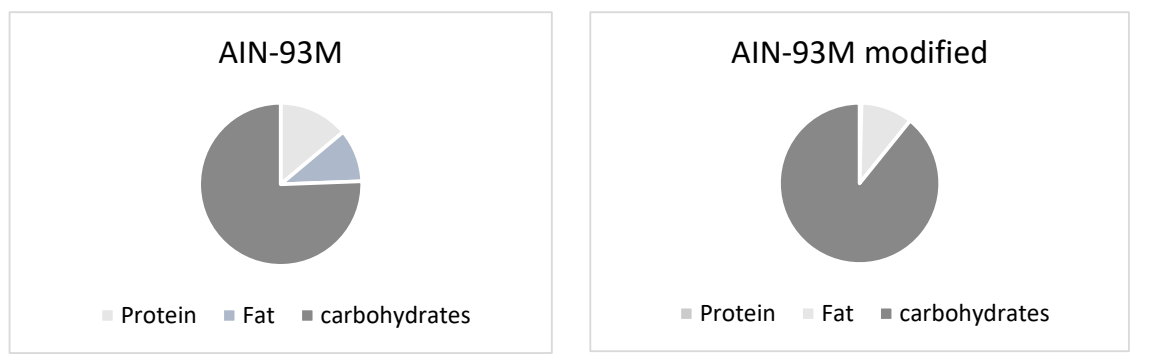

Figure 1. Schematics of complete and protein restricted diets. Each pie is in proportion with the amount of macronutrients in the diet. 
declared by Iranian Ministry of Health. This project was approved by Ethics Committee of Shiraz University of Medical Sciences as well. Prior to the experiment, the protocols were confirmed to be in accordance with the guidelines of Animal Ethics Committee of Shiraz University of Medical Sciences (\# ir.sums.rec. 1395. s379). This study was extracted from PhD thesis of Baran Hashemi at this university (Thesis \#94-01-84-10546).

\section{Statistical analysis}

Data were analyzed with SPSS, version 19, for windows (IBM, Armonk, NY, USA) and Stata software, version 13 (Stata Corp LP, College Station, Texas, USA). Univariate logistic regression model was used to predict the odds of BUN level after MRI. For removing the confounding variables, those with $P$ value less than 0.2 were entered into multivariate regression model. $P$ value $<0.05$ was considered statistically significant.

\section{Results}

Food intake was not different between groups except on day 9 when the protein-restricted group had more food intake than the control group (Figure 2). Fluid consumption was not different between the two groups. Despite no difference in calorie intake between the two groups of pre- and post-surgery $(P=0.7$ and $P=0.2$, respectively), the intervention group had a significant lower weight before surgery $(P=0.01)$. Pre-operative dietary manipulation led to a significant weight reduction in the intervention group $(P=0.005)$. Standard diet, however, caused a significant weight gain in the control group $(P=0.01)$. Despite weight reduction after MRI in both groups, one week after MRI weight was not different between the groups. Pre-operative mortality rate was $15 \%$ in protein restricted and $22 \%$ in the control groups. BUN levels increased significantly compared to the pre-operative level in the control group $(P=0.03)$ and decreased significantly in the protein-restricted group $(P=0.01)$ (Figure 3). Multivariate analysis showed that $\mathrm{PR}$, through its effect on blood glucose $(\beta=1.2,95 \% \mathrm{CI}=0.1$ -

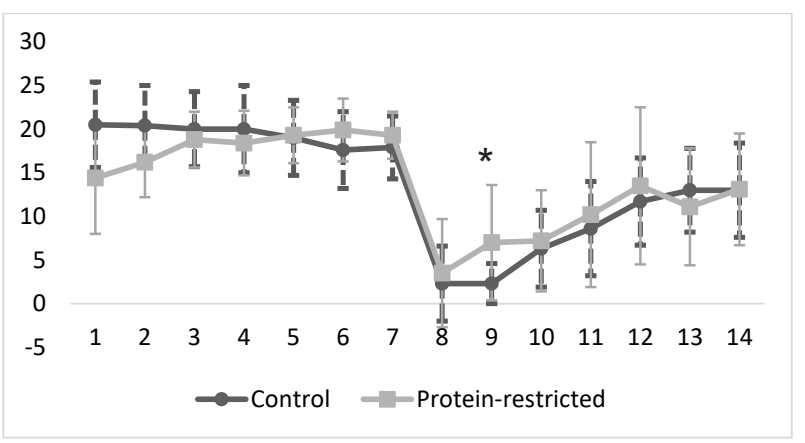

Figure 2. Food intake through the study period. *Significant difference between two groups $(P=0.03)$
2.34), IL-6 $(\beta=-2.22,95 \% \mathrm{CI}=-3.9--0.54)$ and LVEF $(\beta=-$ $1.21,95 \% \mathrm{CI}=-2.34-0.09)$ was able to protect the kidney from MRI (Table 1).

\section{Discussion}

We investigated the effect of one-week PR on the BUN level as a marker of kidney injury after MRI. We also investigated what factors mediate this possible preconditioning effect. Multivariate regression analysis showed that seven days of PR could protect the post-MRI kidney function through modulating IL-6, left ventricular ejection fraction (LVEF) and blood glucose level.

We indicated that post-operative glucose level was positively associated with BUN value one week after MRI. Previous studies showed that hyperglycemia preand peri-operative was accompanied by exacerbating the kidney injury after cardiac surgery (16) and higher long term mortality rate (17). Interestingly, it was found that association of hyperglycaemia with reperfusion injury was stronger in nondiabetic individuals than diabetic ones (16). Furthermore, insulin therapy could normalize the urea nitrogen synthesis in diabetic rats. The mechanism may lie in the anti-glucagon effect of insulin. Hyperglucagonemia has an important role in urea synthesis (18). Additionally, blood glucose management decreases oxidative /nitrative stress in MRI (19) and reduces the kidney injury (20).

We found that higher pre-operative IL- 6 was associated with lower BUN levels after myocardial reperfusion injury. IL-6 has both pro- and anti-inflammatory effect on reperfusion injury. In contrast to our result, some studies found IL-6 devastating effect in renal ischemia/ reperfusion $(21,22)$. Patel et al studied the kidney injury after renal reperfusion injury and found that IL-6 knockout mice and wild-type mice that were injected IL-6 antibody were protected from ischemia/reperfusion injury. Plasma creatinine and urea were lower when IL-6 function was prohibited (21). However, in accordance to our finding, other studies proposed the preconditioning effect of IL-6. Collard and colleagues suggested that inhibition of reperfusion-induced inflammation may

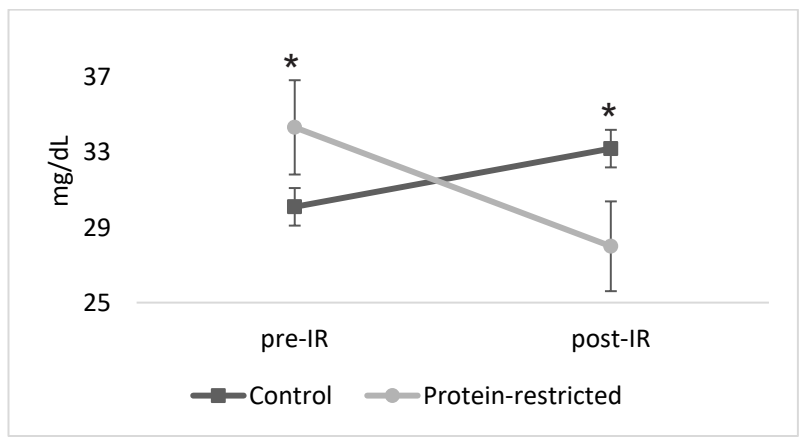

Figure 3. BUN levels. * Significant difference between control and protein-restricted groups after 7 days of dietary manipulation $(P=0.02)$ and at the end of the study $(P=0.004)$. 
Table 1. Prediction of post-MRI BUN value according to univariate and multivariate linear regression analysis

\begin{tabular}{|c|c|c|c|c|c|c|c|c|}
\hline \multirow{3}{*}{ Variables } & \multicolumn{4}{|c|}{ Univariate model } & \multicolumn{4}{|c|}{ Multivariate model } \\
\hline & \multirow{2}{*}{$\beta$} & \multicolumn{2}{|c|}{$95 \% \mathrm{Cl}$} & \multirow{2}{*}{$P$ value } & \multirow{2}{*}{$\beta$} & \multicolumn{2}{|c|}{$95 \% \mathrm{Cl}$} & \multirow{2}{*}{ P value } \\
\hline & & Lower & Upper & & & Lower & Upper & \\
\hline BUN pre-MRI & -1.59 & -4.02 & 0.83 & 0.186 & & & & \\
\hline IL-6 pre-MRI & -2.1 & -4.54 & 0.33 & 0.087 & -2.22 & -3.9 & -0.54 & 0.014 \\
\hline IL-6 post-MRI & 1.42 & -0.19 & 3.04 & 0.08 & & & & \\
\hline LDH pre-MRI & -1.26 & -3.7 & 1.16 & 0.29 & -- & & & \\
\hline LDH post-MRI & 0.28 & -2.7 & 3.27 & 0.842 & -- & & & \\
\hline Glucose pre-MRI & 0.34 & -2.27 & 2.96 & 0.787 & & & & \\
\hline Glucose pre & 1.7 & 0.27 & 3.11 & 0.022 & & & & \\
\hline Glucose post-MRI & 1.59 & 0.05 & 3.14 & 0.044 & 1.2 & 0.1 & 2.34 & 0.035 \\
\hline EF pre-MRI & -1.09 & -3.64 & 1.44 & 0.38 & -- & & & \\
\hline EF post-MRI & -1.54 & -3.07 & 0.01 & 0.095 & -1.21 & -2.34 & -0.09 & 0.037 \\
\hline
\end{tabular}

disrupt the protective physiologic process or result in immunosuppression (23). Preconditioning effect of exercise, ischemic preconditioning, and pharmacological therapy against MRI are mediated by IL-6. In ischemic preconditioning and exercise-induced cardioprotection by IL-6, MAPKs and Janus kinase-signal transducer and activator of transcription (JAK/STAT) signalling pathways are activated (24). It is unclear how PR-induced kidney protection in MRI are mediated by IL-6. Nonetheless, Nechemia-Arbely et al found that prevention of acute kidney injury by IL-6/IL-6R conducts via STAT3 signalling pathway (25).

\section{Conclusion}

We found that short-term PR before MRI would prevent the kidney injury. PR established its effect through modulating three risk factors; pre-operative IL-6, postoperative blood glucose

\section{Authors' contribution}

DA and NN performed some part of the experiments and review of the manuscript. MSM and MM had oversight of research activity planning and execution and review of the manuscript. ZM applied statistical analysis. HB conducted research and investigation process, data collection and preparation of the first draft manuscript.

\section{Conflicts of interest}

The authors declare no conflicts of interest.

\section{Ethical considerations}

Ethical issues (including plagiarism, misconduct, data fabrication, falsification, double publication or submission, redundancy) have been completely observed by the authors.

\section{Funding/Support}

This study was funded by Shiraz University of Medical
Sciences (Shiraz, Fars, Iran) (Grant \# 94-01-84-10546). Rajaie Cardiovascular, Medical and Research Center provided surgical supplies and echocardiography (Tehran, Iran).

\section{References}

1. Karkouti K, Wijeysundera DN, Yau TM, Callum JL, Cheng DC, Crowther M, et al. Acute kidney injury after cardiac surgery. Circulation. 2009;119:495-502. doi: 10.1161/ CIRCULATIONAHA.108.786913.

2. Rosner MH, Okusa MD. Acute kidney injury associated with cardiac surgery. Clin J Am Soc Nephrol. 2006;1:19-32. doi: 10.2215/ CJN.00240605.

3. Schetz M, Vanhorebeek I, Wouters PJ, Wilmer A, Van den Berghe G. Tight blood glucose control is renoprotective in critically ill patients. J Am Soc Nephrol. 2008;19:571-8. doi: 10.1681/ASN.2006101091.

4. Thiele RH, Isbell JM, Rosner MH. AKI associated with cardiac surgery. Clin J Am Soc Nephrol. 2015;10:500-14. doi: 10.2215/ CJN.07830814.

5. Hausenloy DJ, Yellon DM. Ischaemic conditioning and reperfusion injury. Nat Rev Cardiol. 2016;13:193-209. doi:10.1038/nrcardio.2016.5.

6. Brandi L, Frediani M, Oleggini M, Mosca F, Cerri M, Boni C, et al. Insulin resistance after surgery: normalization by insulin treatment. Clin Sci. 1990;79:443-50. doi: 10.1042/ cs0790443.

7. Yang Y, Lang X-b, Zhang P, Lv R, Wang YF, Chen JH. Remote ischemic preconditioning for prevention of acute kidney injury: a meta-analysis of randomized controlled trials. Am J Kidney Dis. 2014;64:574-83. doi: 10.1053/j. ajkd.2014.04.029.

8. Robertson LT, Mitchell JR. Benefits of short-term dietary restriction in mammals. Exp Gerontol. 2013;48:1043-8. doi: 10.1016/j.exger.2013.01.009.

9. van Ginhoven TM, Dik WA, Mitchell JR, Smits-te Nijenhuis MA, van Holten-Neelen C, Hooijkaas H, et al. Dietary restriction modifies certain aspects of the postoperative acute phase response J Surg Res. 2011;171:582-9. doi: $10.1016 /$ j.jss.2010.03.038. 
10. Varendi K, Airavaara M, Anttila J, Vose S, Planken A, Saarma M, et al. Short-term preoperative dietary restriction is neuroprotective in a rat focal stroke. PLoS One. 2014;9: e93911. doi: 10.1371/journal.pone.0093911.

11. Peng W, Robertson L, Gallinetti J, Mejia P, Vose S, Charlip A, et al. Surgical stress resistance induced by single amino acid deprivation requires Gcn2 in mice. Sci Transl Med. 2012;4:118ra11-ra11. doi: 10.1126/scitranslmed.3002629.

12. Robertson LT, Treviño-Villarreal JH, Mejia P, Grondin Y, Harputlugil E, Hine C, et al. Protein and calorie restriction contribute additively to protection from renal ischemia reperfusion injury partly via leptin reduction in male mice. J Nutr. 2015;145:1717-27. doi:10.3945/jn.114.199380.

13. Hewitt SM, Dear J, Star RA. Discovery of protein biomarkers for renal diseases. J Am Soc Nephrol. 2004;15:1677-89. doi: 10.1097/01.ASN.0000129114.92265.32.

14. Stafford-Smith M, Patel UD, Phillips-Bute BG, Shaw AD, Swaminathan M. Acute kidney injury and chronic kidney disease after cardiac surgery. Adv Chronic Kidney Dis. 2008;15:257-77. doi: 10.1053/j.ackd.2008.04.006.

15. Scherrer-Crosbie M, Thibault HB. Echocardiography in translational research: of mice and men. J Am Soc Echocardiogr. 2008;21:1083-92. doi: 10.1016/j. echo.2008.07.001.

16. Stolker JM, McCullough PA, Rao S, Inzucchi SE, Spertus JA, Maddox TM, et al. Pre-procedural glucose levels and the risk for contrast-induced acute kidney injury in patients undergoing coronary angiography. J Am Coll Cardiol. 2010;55:1433-40. doi: 10.1016/j.jacc.2009.09.072.

17. Su H, Sun X, Ma H, Zhang H-F, Yu Q-J, Huang C, et al. Acute hyperglycemia exacerbates myocardial ischemia/ reperfusion injury and blunts cardioprotective effect of GIK. Am J Physiol Endocrinol Metab. 2007;293:E629-E35.

18. Almdal T, Vilstrup H. Strict insulin therapy normalises organ nitrogen contents and the capacity of urea nitrogen synthesis in experimental diabetes in rats. Diabetologia. 1988;31:114-8.

19. Ji L, Fu F, Zhang L, Liu W, Cai X, Zhang L, et al. Insulin attenuates myocardial ischemia/reperfusion injury via reducing oxidative/nitrative stress. Am J Physiol Endocrinol Metab. 2010;298:E871-E80.

20. Bellomo R, Auriemma S, Fabbri A, D’onofrio A, Katz $\mathrm{N}$, McCullough P, et al. The pathophysiology of cardiac surgery-associated acute kidney injury (CSA-AKI). Int J Artif Organs. 2008;31:166-78.

21. Patel NS, Chatterjee PK, Di Paola R, Mazzon E, Britti D, De Sarro A, et al. Endogenous interleukin-6 enhances the renal injury, dysfunction, and inflammation caused by ischemia/ reperfusion. J Pharmacol Exp Ther. 2005;312:1170-8. doi:10.1124/jpet.104.078659.

22. Zhang WR, Garg AX, Coca SG, Devereaux PJ, Eikelboom J, Kavsak P, et al. Plasma IL-6 and IL-10 concentrations predict $\mathrm{AKI}$ and long-term mortality in adults after cardiac surgery. J Am Soc Nephrol. 2015;26:3123-32. doi: 10.1681/ ASN.2014080764.

23. Collard CD, Gelman S. Pathophysiology, clinical manifestations, and prevention of ischemia-reperfusion injury. The Journal of the American Society of Anesthesiologists. 2001;94:1133-8.

24. McGinnis GR, Ballmann C, Peters B, Nanayakkara G, Roberts M, Amin R, et al. Interleukin-6 mediates exercise preconditioning against myocardial ischemia reperfusion injury. Am J Physiol Heart Circ Physiol. 2015;308:H142333. doi: 10.1152/ajpheart.00850.2014.

25. Nechemia-Arbely Y, Barkan D, Pizov G, Shriki A, RoseJohn S, Galun E, et al. IL-6/IL-6R axis plays a critical role in acute kidney injury. J Am Soc Nephrol. 2008;19:1106-15. doi: 10.1681/ASN.2007070744.

Copyright (c) 2019 The Author(s); Published by Nickan Research Institute. This is an open-access article distributed under the terms of the Creative Commons Attribution License (http://creativecommons.org/licenses/by/4.0), which permits unrestricted use, distribution, and reproduction in any medium, provided the original work is properly cited. 